\title{
The medical ethnobotany of Lesotho: a review
}

\author{
A. MOTEETEE*† and B-E. VAN WYK*
}

Keywords: ethnobotany, Lesotho, magic, materia medica, medicine, traditional healers

\section{ABSTRACT}

\begin{abstract}
Traditional healing in Lesotho is reviewed, focusing on four aspects: 1, cultural practices; 2 , traditional health care practitioners; 3, dosage forms; 4 , the materia medica. Cultural practices are strongly associated with the belief that intangible forces are responsible for human happiness and misery. A total of 303 plant species are used medicinally (including 25 alien species), representing eight pteridophyte and 75 angiosperm families, of which the most important are Asteraceae, Fabaceae, Hyacinthaceae, Apocynaceae, Scrophulariaceae, Lamiaceae and Poaceae. Dicoma anomala (used mainly for digestive ailments) and Artemisia afra (used mainly for respiratory ailments) appear to be the best known and most widely used medicinal plants amongst a total of 37 species that have been cited four or more times in the literature. About 50 species are variously employed for magic and sorcery. There are no new species records but 36 new uses are reported. Our conclusion is that the medicinal plants of Lesotho are relatively well recorded and that this review will allow detailed comparisons with other African healing cultures.
\end{abstract}

\section{INTRODUCTION}

Traditional healing has always been practised in Lesotho from time immemorial, but the concepts, practices and materia medica are not well known beyond the borders of the country and have not yet been systematically recorded. This paper is therefore aimed at providing a broad review of traditional medicine in Lesotho, focusing on cultural practices, traditional health care practitioners and especially the botanical identity, vernacular names, uses and dosage forms of the plants that are used.

There are three reasons why we are hesitant to call this a review of Sotho traditional medicine. Firstly, it is difficult to delimit the geographical boundaries of the Sotho culture, e.g. should North Sotho (Pedi) - excluded here-be included? Secondly, there are subtle linguistic differences, in terminology and plant names, for example between the Sesotho spoken in Lesotho and that which is spoken in other parts of southern Africa. Thirdly, the plant species used in Lesotho sometimes differ from the species found in other regions. However, even though this review is focused on Lesotho, the information probably has a much wider relevance and application than the boundaries of a single, small country.

\section{Sources of information}

The review is based on the experience and recollections of the first author and on the available literature. These experiences and recollections stem from early life (until 20 years ago) of the first author; many of these plants were used in her home and village in the rural areas of the Qacha's Nek District and later in the Maseru District in Lesotho. Further information regarding plant use was gathered through discussions and interviews with informants using Sesotho names of plants and in some cases with voucher specimens. The most comprehensive reference material is that of Phillips (1917)

\footnotetext{
* Department of Botany and Plant Biotechnology, University of Johannesburg, P.O. Box 524, 2006 Auckland Park, Johannesburg.

$\uparrow$ Corresponding author e-mail address: amoteetee@uj.ac.za. MS. received: 2010-03-11.
}

but the list of plants is incomplete and many of the names are outdated. Jacot Guillarmod (1971) also gives an account of plant use but her main source was Phillips (1917). Other useful sources of information include Watt \& Breyer-Brandwijk (1962), Motlamelle (1938), Schmitz (1982) and Maliehe (1997), of which the last three are out of print. The last-mentioned is limited to 60 species of useful plants in Lesotho. Some valuable information has also been published in early volumes of Bantu studies (Watt \& Brandwijk 1927) and in lesser known publications such as Casalis (1861) and Ashton (1967). A comprehensive list of medicinal plants which includes the scientific names, author citations, vernacular names and main uses, is presented in the Appendix. Authorities for scientific names are not repeated in the text.

\section{Cultural practices}

Three important aspects, medicine (moriana, litlhare), magic (lithlare), and sorcery (boloi) play an important role in the Basotho culture.

\section{Medicine (moriana, litlhare)}

Many people in Lesotho, particularly those in rural areas with no clinics or health facilities, are able to diagnose and treat minor common ailments such as colds, coughs, headaches and constipation. This self-medication relies almost exclusively on medicinal plants. Headaches, for example, can simply be cured by inhaling smoke from a burning stick of monkhoane (Heteromorpha aborescens), stomach aches by chewing roots of a grass known as hloko (Elionurus muticus) (Motlamelle 1938). If there is no cure, a traditional healer is consulted. Women are traditionally experts in home remedies because they collect vegetables (moroho), many of which are also used for medicinal purposes. Historically however, most traditional healers are men. There are two main reasons for this: 1 , there is a strong traditional belief that women should perform their duties at home, taking care of their families, including children and the elderly; 2, there are taboos around women handling strong medicines. 
If there was an epidemic in a village, the village doctor or chief's doctor (at the chief's expense), usually a diviner (selaoli) or herbalist (ngaka-chitja), would prepare a mixture (known as leliba) that would have to be taken by all the villagers.

\section{Magic (lithlare)}

Medicines are not only used to cure illnesses but are used for almost any situation, including those that occur when a need for help in controlling natural or social phenomena is perceived. This category includes plants that are used as Category 1, good luck charms, such as molomo-monate (Lotononis eriantha var. obovata) which is a very well-known plant used to 'make sure you are heard wherever you go' (e.g. litigants use it to strengthen their case.); Category 2 includes plants that are used as love philtres such as Cymbopogon marginatus which may be added to a man's bathing water while he calls out the name of the desired woman; Category 3 includes plants that are used as charms against lightning, thunderstorms and hailstorms such as Phygelius aequalis (metsimatso) which is a renowned charm to protect crops from hail damage. The Basotho believe that good health is not only physical but also spiritual; therefore ancestral spirits (balimo) form an integral part of their lives. If a person experiences bad luck and misfortune, then this is most likely ascribed to the fact that they have neglected their ancestors and are therefore being punished.

\section{Sorcery (boloi)}

There is a strong belief in sorcery among the people of Lesotho, so much so that misfortune, accident, unusual illness, or even death may be attributed to it. Sorcerers are believed to use special or ordinary medicines maliciously. It was previously believed that they were even capable of and responsible for harming whole communities through disasters and epidemics (Ashton 1967). Therefore, it was (and still is) a socially unacceptable practice. Although killing alleged sorcerers was proclaimed illegal by King Moshoeshoe I in 1855 (Ashton 1967), people suspected of sorcery were often severely punished, sometimes even brutally tortured to death (Casalis 1861). This practice, however, appears to have discontinued in the last 50 years. Sorcery is believed to be driven either by jealousy (mostly) or by revenge. The effects of sorcery range from a minor injury or illness

(such as diarrhoea or stomach ache believed to be due to worms, beetles or small snakes introduced into the patient's body, often from eating bewitched food), or more serious conditions such as convulsions (due to strangling by a familiar (a supernatural being), i.e. a thokolosi), or death by lightning. When sorcery is suspected, a diviner is consulted, who will then, as the first step, counteract the witchcraft by renewing all protective medicines. Sometimes the patient is taken and hidden away in another village. If nothing works, then people who believe themselves to be victims of sorcery have sometimes been driven to murdering the suspected sorcerer (Ashton 1967).

\section{Traditional healthcare practitioners}

Several types of traditional healthcare practitioners exist in Lesotho. These include: the diviner or bone thrower (ngaka, selaoli), the herbalist (ngaka chitja), the seer (senohe), the veterinarian (ngaka-ea-liphoofolo), the sangoma (lethuela, mokoma, leqekha), the apprentice (lehlahana) and the charlatan (ngakana-ka-hetla). The Sesotho word ngaka is a generic term applied to any kind of healer or doctor, but some authors (e.g. Motlamelle 1938) apply it exclusively to the diviner. Although traditional healers do not have any special status in society, the chief formerly had a doctor who occupied a socially high-ranking position next to him or her. These doctors associated with the chiefs were rainmakers (seepa-meru), diviners (ngaka, selaoli) and keepers of war medicine.

When consulting a healer, one is expected to pay an initial consultation fee (usually a sheep or goat) to 'open the bag of medicines'. In the case of a diviner, the fee is known as pula-molomo, which literally translated means 'one that opens (bula) the mouth (molomo)' [pula is the noun form of bula, not to be confused with pula (rain), which is written in the same way but pronounced differently]. Pula-molomo therefore has to be paid before the diviner will even speak. It is not customary to say 'thank you' when given medicine because this will weaken its strength. Final payment is done only if the treatment has worked.

\section{Diviner (Ngaka, Selaoli)}

The diviner uses bones (litaola) to help him make a diagnosis and discern the appropriate treatment. The diagnosis is based on the way in which the various bones land or fall on the ground, having been thrown by the person consulting. Diviners are expected to solve problems of any kind; they prescribe remedies for minor ailments, protection against sorcery, misfortune and accidents, and also for good luck and prosperity. 'There is, in fact, no manner of question which the diviners do not undertake to answer' (Casalis 1861). Traditionally, he is a striking figure and may be recognised by his headdress (kuoane), made from monkey skin and decorated with feathers, gall bladders and eagle's claws, a shoulder strap of horns (lenaka) from various beasts containing all kinds of powders and ointments (known as mohlabelo) and, a bag of divining bones (khetsi) consisting of varying pairs of bones from different animals (Ashton 1967).

\section{Herbalist (Ngaka-chitja)}

Traditional healers who rely only on plants are known in Sesotho as ngaka-chitja which means a hornless doctor, because they do not keep medicines in horns. They diagnose and treat minor ailments and, traditionally, if they are unable to cure the disease, they refer patients to a diviner. In recent times they are known also to refer patients to a clinic.

\section{Seer (Senohe)}

The seer is a person with the power of second sight, meaning that they divine supernaturally. This power is a skill that cannot be acquired but is believed to be a gift from the ancestors. A seer can diagnose illnesses and foretell the future. A special type of seer can locate (see) people who have drowned or have been swallowed by the water serpent, khanyapa or noha-ea-metsi (Ash- 
ton 1967). Chief Mohlomi, a very well-known leader in Lesotho's history, who was an advisor, mentor, and doctor to the founder of the Basotho nation, King Moshoeshoe I, was a seer by profession.

\section{Veterinarian (Ngaka-ea-liphoofolo)}

Historically, there were no doctors devoted entirely to animal illnesses; this was the job of diviners, herbalists or seers. However, the existence of veterinarians is now recognised. Animals such as cattle, Basotho ponies, sheep and goats play an important role in the Basotho culture. Cattle are symbolic in Lesotho, being used for lobola (bohali) and may also be slaughtered during burial rituals to accompany (ho felehetsa) deceased persons so they can rest in peace. In addition, cattle represent wealth. Many areas in Lesotho are still only accessible by horses and they therefore serve as a useful mode of transport. Sheep and goats are kept mainly for meat and wool. It is therefore imperative that all these animals are kept healthy. Veterinarians work in a similar manner as herbalists; they are able to diagnose and treat a wide range of animal diseases including gall sickness, 'black leg' and lung sickness.

\section{Sangoma (Lethuela, Mokoma, Leqekha)}

The concept of a sangoma is foreign to the Lesotho culture and it was introduced by the Thembus who originated from what was then known as the Cape Colony (Motlamelle 1938; Ashton 1967), perhaps currently the Eastern Cape Province. The language in which sangomas practise their craft points to the foreign origins of this tradition. Furthermore, sangomas are mostly women, whereas in Lesotho, healers were traditionally male only. When consulted, they diagnose problems using the divining method (in a similar manner as diviners, except that their bag of bones also includes sea shells and lately a set of dice) and prescribe medicines.

\section{Apprentice (Lehlahana)}

Diviners and herbalists learn their profession by becoming an apprentice (lehlahana) to a reputable healer. Among other duties, the lehlahana carries the teacher's bag, cooks the food, collects the fees, collects and prepares the medicines and performs techniques such as making incisions (ho phatsa) (Motlamelle 1938). Once qualified, the apprentice may establish his or her own practice, or on rare occasions he or she may inherit the master's horn. Other healers inherit prescriptions from their family members who are doctors.

\section{Charlatan (Ngakana-ka-hetla)}

While we disagree with Casalis' (1861) assertion that traditional healers are 'a crowd of clever and cunning men, who, under the generic name of engakas, or learned men, perform functions of priests, prophets, diviners, and doctors, and enrich themselves at the public expense', there are traditional healers who are charlatans. These are termed ngakana-ka-hetla (the verb hetla means to look over your shoulder) in Sesotho, a mocking word applied to people who claim to be healers but have not undergone proper training. As a result they have to keep looking over their shoulders to make sure they are not being followed by the patients whom they have cheated.

\section{Dosage forms and methods of administering medicine}

Medicinal plants are used in many different forms. They are taken as decoctions (mostly with water, rarely with milk) or infusions either orally (ho noa) or as an enema (ho tšela) for various internal ailments. Plants are also incinerated, powdered and used as a snuff (ho tsuba), often to induce sneezing to get rid of head and chest colds. Another form is inhalation of either smoke from a burning plant (another form of ho tsuba) or vapour from a freshly crushed plant or fresh leaves of lengana (Artemisia afra) or koena (Mentha longifolia) stuffed in the nostrils, as a cure for headaches and colds. Smoke can also be introduced into the body through fumigation (ho futhela). Boiling decoctions (generally of some Helichrysum species, Artemisia afra or Mentha longifolia) are used for steaming (ho arubela) to treat colds. Sometimes plants are also taken as masticatories, although only a few plants are chewed raw (e.g. Alepidea cordifolia and Elionurus muticus). Other medicines are applied or rubbed into incisions/scarifications (ho phatsa) made on the body. These incisions are done for two reasons: 1, to protect people against sorcery or to counteract its effects, in which case several parts of the body (including forehead, cheeks, chin, neck, throat, breasts, and joints) are scarified and the medicine is rubbed in; or 2, as a cure for ailments such as headaches, whereby only the affected part is scarified. Other plants are used externally as lotions, mixed with fat to make ointments or applied as poultices (ho thoba or ho tapisa).

\section{Materia medica}

A checklist of medicinal plants used in Lesotho is presented in the Appendix. The list is arranged alphabetically according to family and genus. Several plant species used for magical purposes and during the divining process (e.g. for washing the divining bones) have also been included in the list. The botanical nomenclature in older publications has been updated to reflect currently accepted names, following Germishuizen \& Meyer (2003).

The appendix reveals that 355 plant species (including 23 exotics), from eight pteridophyte and 76 angiosperm families, are used for various medicinal purposes in Lesotho. In terms of the number of medicinal species, the most important families are Asteraceae (76), Fabaceae (33), Hyacinthaceae (15), Apocynaceae (12), Scrophulariaceae (12), Lamiaceae (11) and Poaceae (11). It is also interesting to note that seven species of ferns are used medicinally-mostly used to treat headaches, either through smoking the leaves or inhaling smoke from smouldering leaves.

Some plants are age and gender specific, others are strictly for livestock, whereas others are used for both humans and animals. Several plants are used to treat children's ailments. From the Appendix, the following pattern of exclusive uses emerges: human (287 species), livestock (8 species), women (20 species), men (three species) and children (29 species). The medicinal plant uses can also be grouped on the basis of the ailment treated, such as problems relating to digestion (84 species), respiration (67 species), fertility and reproduc- 
tion (31 species), circulation (26 species) and skin and wounds ( 24 species). Another important category is that of magic and sorcery; at least 50 species are used for this purpose. For the sake of brevity, a more detailed analysis is not given here, but the necessary data for more comprehensive analyses are available in the Appendix.

Interesting examples of specific uses include the following. Plants used exclusively for children include Brachystelma foetidium (colds), Helichrysum ecklonis (diarrhoea) and Euphorbia clavarioides (skin rashes). Numerous plants are used specifically by women for infertility (e.g. Ajuga ophrydis, Equisetum ramosissimum and Haplocarpha scaposa); menstrual pains (e.g. Gunnera perpensa, Scabiosa columbaria) or for ailments associated with pregnancy such as heartburn, flatulence and colic (e.g. Anthospermum rigidum, Gazania linearis, and Convolvulus bidentatus). Plants used to treat animals only include Watsonia densiflora (for diarrhoea in calves) and Acrotome inflata (for 'black leg' in cattle).

Based on the frequency of published and unpublished records (Appendix), it is possible to rank the species and in this way determine which ones are the best known and/or most frequently used. A total of 37 species in the Appendix have at least four citations for medicinal uses - and almost invariably the same number of citations for vernacular name(s). These 37 species may be considered as the most important and best known medicinal plants in Lesotho and are therefore shown in bold type in the Appendix. The number of citations for vernacular names and for uses were both considered and are given in Table 1.

It is interesting to note that the two most important medicinal plants in the materia medica of Lesotho are used also for the two most common everyday ailments, namely respiratory and digestive problems (Artemisia afra and Dicoma anomala). Artemisia afra (lengana) is most commonly used as a nasal plug but the leaves are also used as a decoction or for steaming. The plant is used as a traditional medicine in many parts of Africa, to treat various illnesses including colds, sore throat, headaches and intestinal worms, but should not be used in high doses as it usually contains thujone, which is a central nervous system toxin (Van Wyk \& Wink 2004). Dicoma anomala (hloenya: to grimace, because of the extremely bitter taste) is used for a wide range of illnesses including diarrhoea, toothache, hypertension, diabetes, period pains, pneumonia, backache, wounds and sores, and for gall sickness in cattle. In South Africa and Zimbabwe, it is used for similar digestive and respiratory ailments (Van Wyk \& Gericke 2000).

Another plant ranking amongst the top in importance is Pentanisia prunelloides, appropriately named setima-mollo (fire extinguisher) in Sesotho for its use to relieve the burning pain of boils and reducing fevers. Urtica urens (bobatsi: something that is rough) is interestingly not indigenous to Lesotho but is also amongst the list of commonly used plants. Other important plants include Gerbera pilloseloides (tsebe-ea-pela: ear of the rock-rabbit), Helichrysum caespititium (phate-ea-ngaka: mat of the healer, because of the prostrate habit), Mentha longifolium (koena: crocodile, because of its association with aquatic environments), Rhamnus prinoides (mofifi: very dark, because of the dark green foliage), Alepidea cordifolia (lesoko), Heteromorpha arborescens (monkhoane), Felicia muricata ('ma-mileng: along the road), Gerbera viridiflora (moarubetso: the one used to fumigate), Helichrysum odoratissimum (phefo: breeze, allegedly because when burnt during harvesting it brings about a breeze that helps with winnowing), Cotyledon orbiculata (serelile: slippery), Trifolium burchellianum ('musa-pelo: the one who turns the heart around), Gunnera perpensa (qobo), Olea europaea (mohloare), Hermannia depressa (seletjane: a small axe), Eucomis undulata (khapumpu), Bulbine narcissifolia (khomo-eabalisana: a cow of the shepherds), Dianthus basuticus (hlokoana-la-tsel: the grass of the road), Mentha aquatica (koena-e-nyenyane: the small crocodile), Cussonia paniculata (motšetse), Gazania krebsiana (tsikitlane), Xysmalobium undulatum (poho-tšehla: yellow bull) and Tulbaghia acutiloba (sefotha-fotha). The traditional use of Mentha aquatica and M. longifolia for respiratory problems can be ascribed to the presence of a volatile oil with possible decongestant effects (Van Wyk \& Gericke 2000). Xysmalobium undulatum is used all over south-

TABLE 1.-No. times vernacular names cited and no. times uses cited for taxa

\begin{tabular}{|c|c|c|c|c|}
\hline 7,7 & 6,6 & 5,5 & 5,4 & 4,4 \\
\hline Artemisia afra & Gerbera pilloseloides & Alepidea cordifolia & Bulbine narcissifolia & Ajuga ophrydis \\
\hline \multirow[t]{15}{*}{ Dicoma anomala } & Helichrysum caespititium & Cotyledon orbiculata & Dianthus basuticus & Albuca setose \\
\hline & Mentha longifolium & Eucomis undulata & & Aloe striatula \\
\hline & Olea europaea & Gerbera viridiflora & & Crassula peploides \\
\hline & Rhamnus prinoides & Gunnera perpensa & & Cussonia paniculata \\
\hline & & Helichrysum odoratissimum & & Euclea crispa \\
\hline & & Hermannia depressa & & Gazania krebsiana \\
\hline & & Heteromorpha arborescens & & Gladiolus crassifolius \\
\hline & & Pentanisia prunelloides & & Hibiscus microcarpus \\
\hline & & Trifolium burchellianum & & Hypoxis argentea \\
\hline & & & & Mentha aquatic \\
\hline & & & & Scabiosa columbaria \\
\hline & & & & Stachys aethiopica \\
\hline & & & & Urtica urens \\
\hline & & & & Vernonia hirsuta \\
\hline & & & & Withania somnifera \\
\hline
\end{tabular}


ern Africa for stomach problems and for a similar purpose in modern phytotherapy - it contains uzarin which has proven anti-diarrhoeal properties (Van Wyk \& Wink 2004).

Although the meaning of some Sesotho plant names is not obvious, many of them are descriptive and indicate either the habit or the usage of the plant (Moteetee \& Van Wyk 2006). For example, Stapelia grandiflora (bohatsu: numbness) is used to cure numbness of the limbs, Asclepias aurea (mohlatsisa; emetic) is used as an emetic to treat constipation, Senecio erubescens (letapiso; poultice) is used as a hot poultice, Scabiosa columbaria (selomi: one that causes pain or bites) is used to relieve period pains and Gomphocarpus fruticosus (moithimolo: one who causes sneezing) is used to cure headaches and colds by sneezing. Several plants known as 'musa-pelo are used as sedatives and adaptogens, for dropsy of the heart or heart palpitations. This concept has been dealt with in detail elsewhere (Moteetee \& Van Wyk 2007).

Animal products are also used for medicinal purposes. Examples include cow dung (used to cure chickenpox), dog fur (placed on a dog-bite wound to speed up the healing process), a mixture of powdered mare's afterbirth and crocodile skin (to assist difficult childbirth; fumigation with smoke from crocodile skin is an alternative). Snake flesh mixed with Linum thunbergii (bohloko) is used to treat snakebite.

\section{CONCLUSIONS}

The most important plants that are used in Basotho traditional medicine and the main health care practitioners and their practices have been described and conceptualized for the first time. A total of 355 plant species are used, representing eight pteridophyte and 76 angiosperm families of which the Asteraceae, Fabaceae, Hyacinthaceae, Apocynaceae, Scrophulariaceae, Lamiaceae and Poaceae are the most important. The traditional system appears to be dynamic and adaptive, because at least 25 alien species have been incorporated into the materia medica.

Plants are used for a wide range of ailments, the most frequent indications being digestive ailments and respiratory conditions. Dicoma anomala (used mainly for digestive ailments) and Artemisia afra (used mainly for respiratory ailments) appear to be the best known and most widely used medicinal plants. Fifty-two species are variously employed for magic and sorcery. Other important medicinal species include Gerbera pilloseloides, Helichrysum caespititium, Mentha longifolium, Rhamnus prinoides, Alepidea cordifolia, Heteromorpha arborescens, Felicia muricata, Gerbera viridiflora, Helichrysum odoratissimum, Cotyledon orbiculata, Trifolium burchellianum, Gunnera perpensa, Olea europaea, Pentanisia prunelloides, Hermannia depressa, Eucomis autumnalis, Bulbine narcissifolia and Dianthus basuticus.

Although hitherto scattered in the literature, the medicinal plants of Lesotho seem to be relatively well recorded, as this review did not reveal any new species records. Detailed comparisons with other African heal- ing cultures are now possible. The data suggest that the uses of the plants were not comprehensively recorded, as 36 new uses are reported. Field surveys in remote parts of Lesotho may reveal additional species and use records, but we believe that we have presented a reasonably comprehensive insight into the diversity of Lesotho medicinal plants and practice.

\section{ACKNOWLEDGEMENTS}

The University of Johannesburg is thanked for financial support. The first author acknowledges all interviewees and family members who provided some information on traditional plant use.

\section{REFERENCES}

ASHTON, H. 1967. The Basuto, a social study of traditional and modern Lesotho: 283-318. Oxford University Press, London.

BRENDLER, T. \& VAN WYK, B-E. 2008. A historical, scientific and commercial perspective on the medicinal use of Pelargonium sidoides (Geraniaceae). Journal of Ethnopharmacology 119: $420-433$.

CASALIS, E. 1861. The Basutos; twenty-three years in South Africa: 1-355. Nosbert, London.

GERMISHUIZEN, G. \& MEYER, N.L. 2003. Plants of southern Africa: an annotated checklist. Strelitzia 14. National Botanical Institute, Pretoria.

GERMISHUIZEN, G., MEYER, N.L., STEENKAMP, Y. \& KEITH, M. 2006. A checklist of South African plants. Southern African Botanical Diversity Network Report No. 41. SABONET, Pretoria.

HUTCHINGS, A. \& VAN STADEN, J. 1994. Plants used for stressrelated ailments in traditional Zulu, Xhosa and Sotho medicine. Part 1: plants used for headaches. Journal of Ethnopharmacology 43: 89-124.

JACOT GUILLARMOD, A. 1971. Flora of Lesotho. Cramer, Lehre.

MALIEHE, E.B. 1997. Medicinal plants and herbs of Lesotho. Mafeteng Development Project, Lesotho.

MOTEETEE, A. \& VAN WYK, B-E. 2006. Sesotho names for exotic and indigenous edible plants in southern Africa. Bothalia 36: 25-32.

MOTEETEE, A. \& VAN WYK, B-E. 2007. The concept of 'musa-pelo and the medicinal use of shrubby legumes (Fabaceae) in Lesotho. Bothalia 37: 75-77.

MOTLAMELLE, M.P. 1938. Ngaka ea Mosotho. Morija Printing Works, Lesotho.

PHILLIPS, E.P. 1917. A contribution to the flora of the Leribe Plateau and environs. Annals of the South African Museum 16: 1-379.

SCHMITZ, M.O. 1982. Wild flowers of Lesotho. ESSA, Roma, Lesotho.

SHALE, T.L., STIRK, W.A. \& VAN STADEN, J. 1999. Screening of medicinal plants used in Lesotho for anti-bacterial and anti-inflammatory activity. Journal of Ethnopharmacology 67: 347-354.

VAN WYK, B-E. \& GERICKE, N. 2000. People's plants: a guide to useful plants of southern Africa. Briza Publications, Pretoria.

VAN WYK, B-E. \& WINK, M. 2004. Medicinal plants of the world. Briza Publications, Pretoria.

WATT, J.M. \& BRANDWIJK, M.G. 1927. Suto (Basuto) medicines. Bantu Studies 3: 73-100, 154-178, 296-319.

WATT, J.M. \& BREYER-BRANDWIJK, M.G. 1962. The medicinal and poisonous plants of southern and eastern Africa. Livingstone, Edinburgh. 


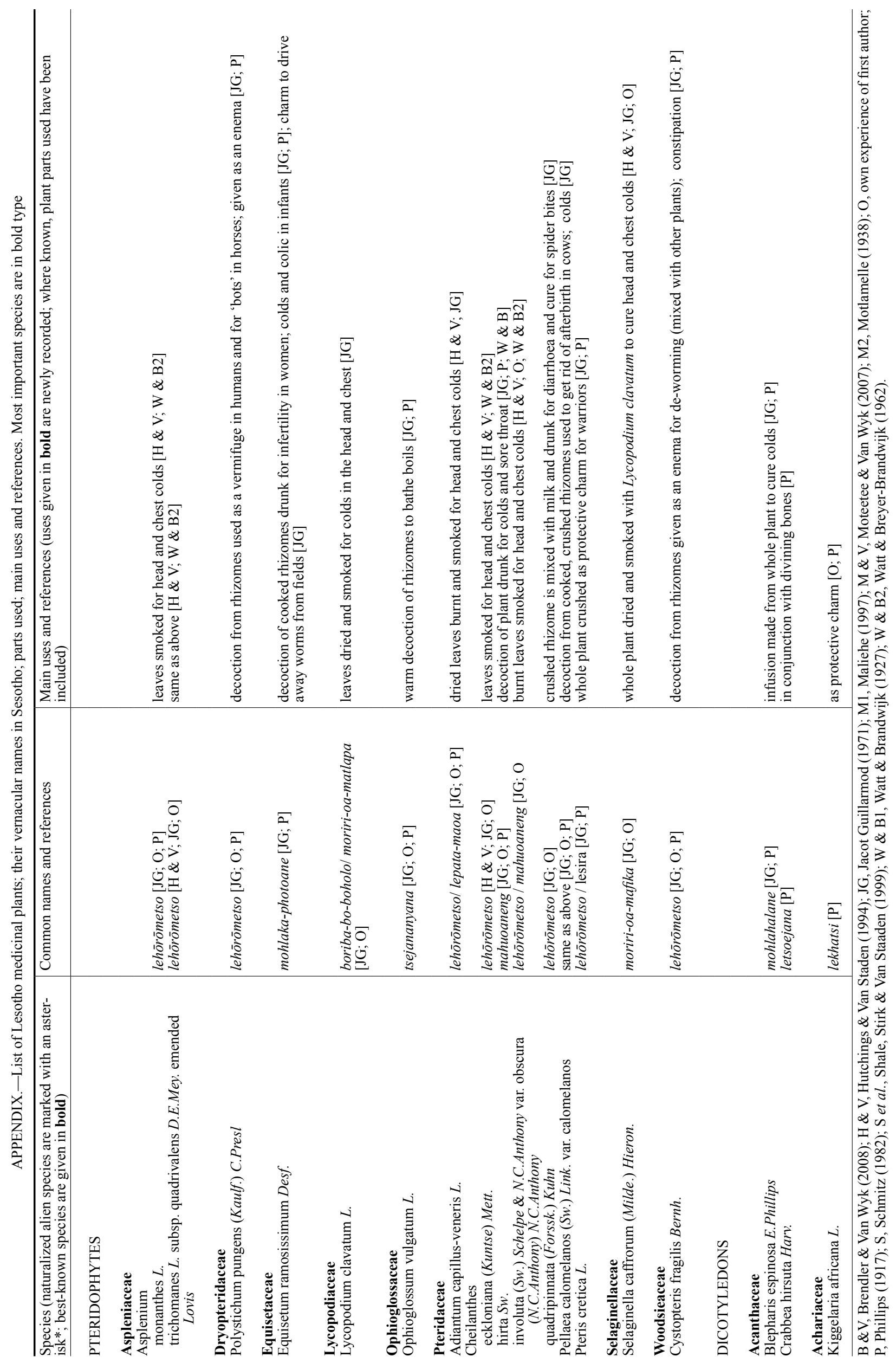




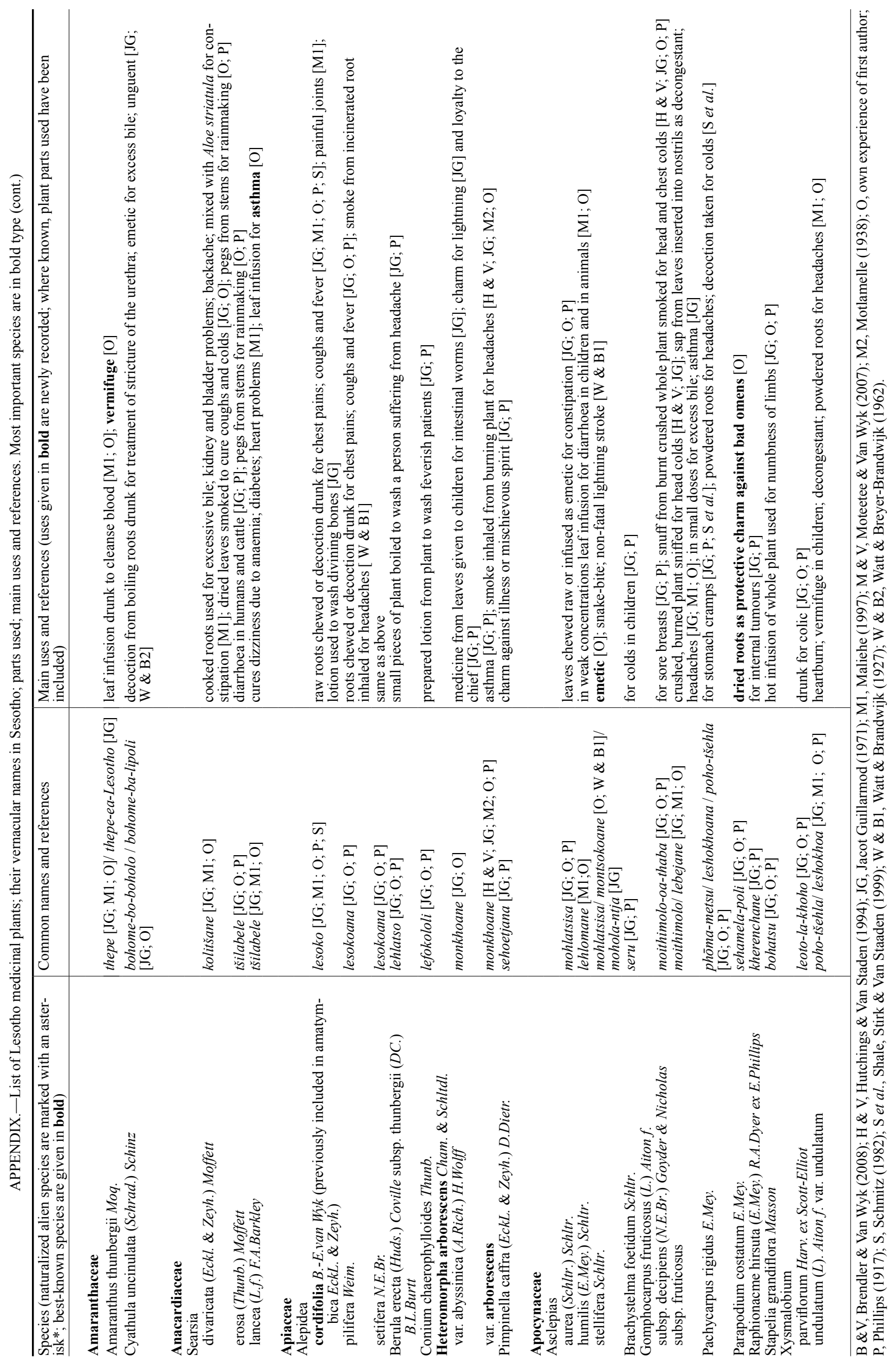




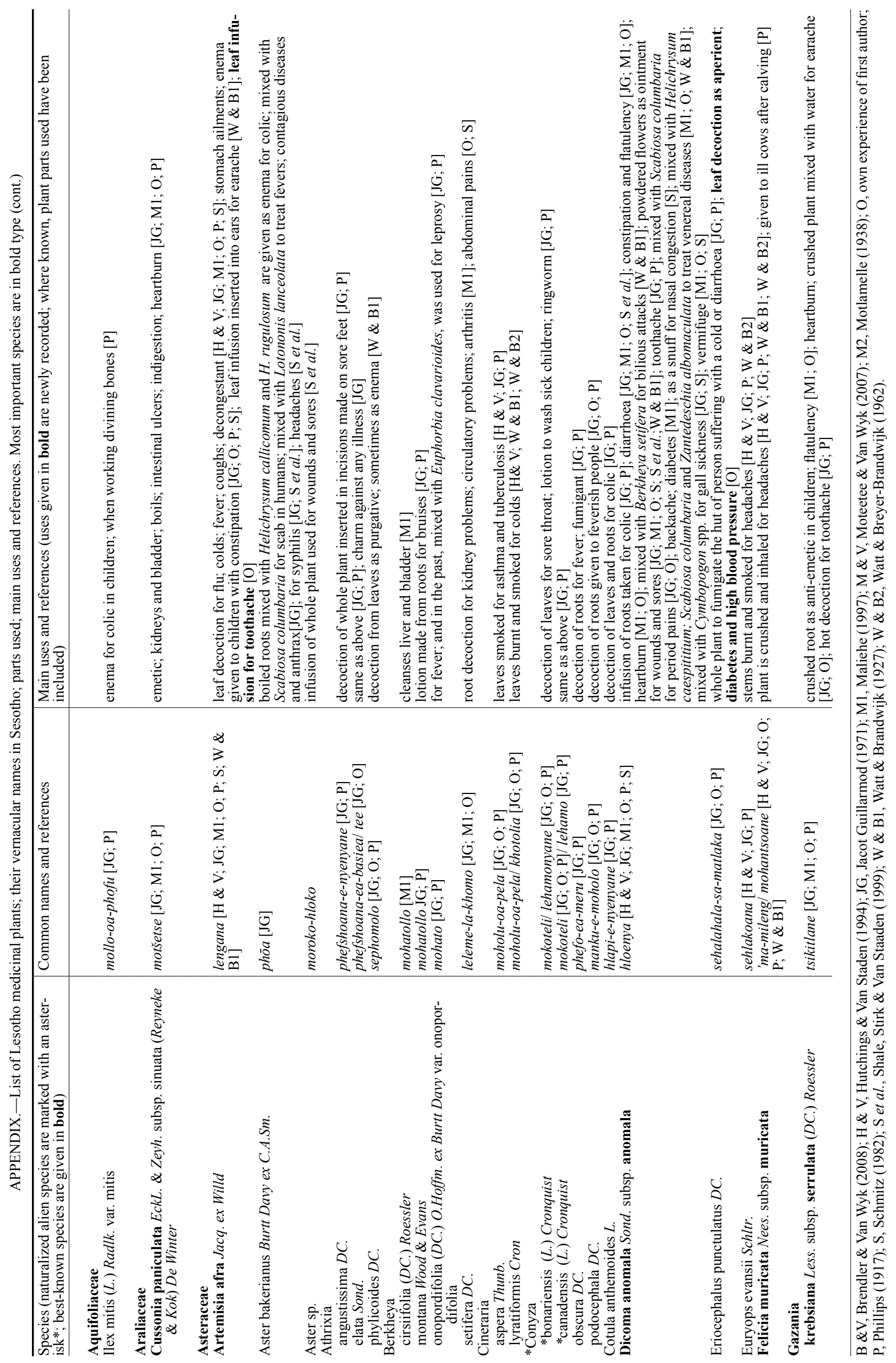




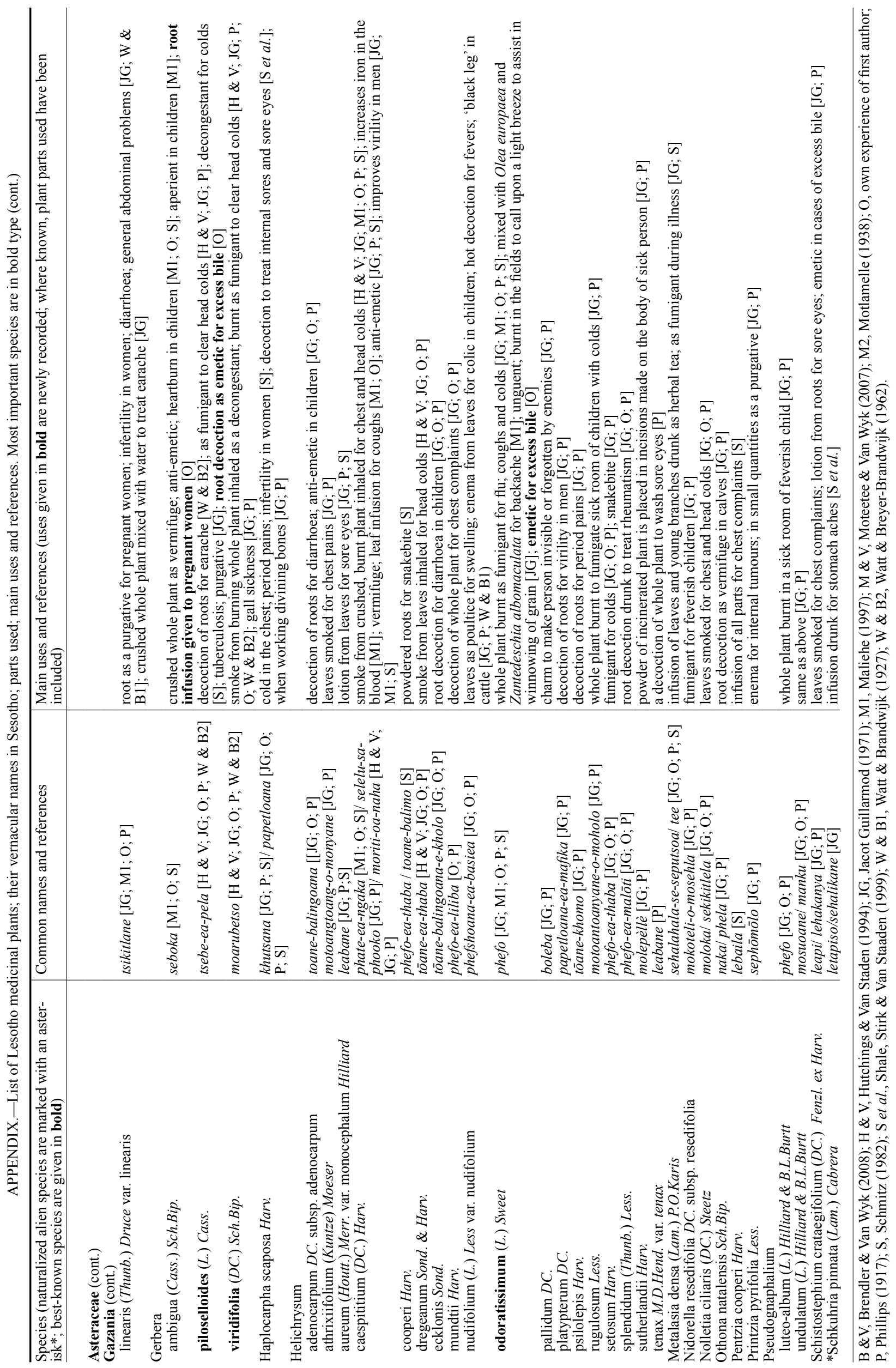




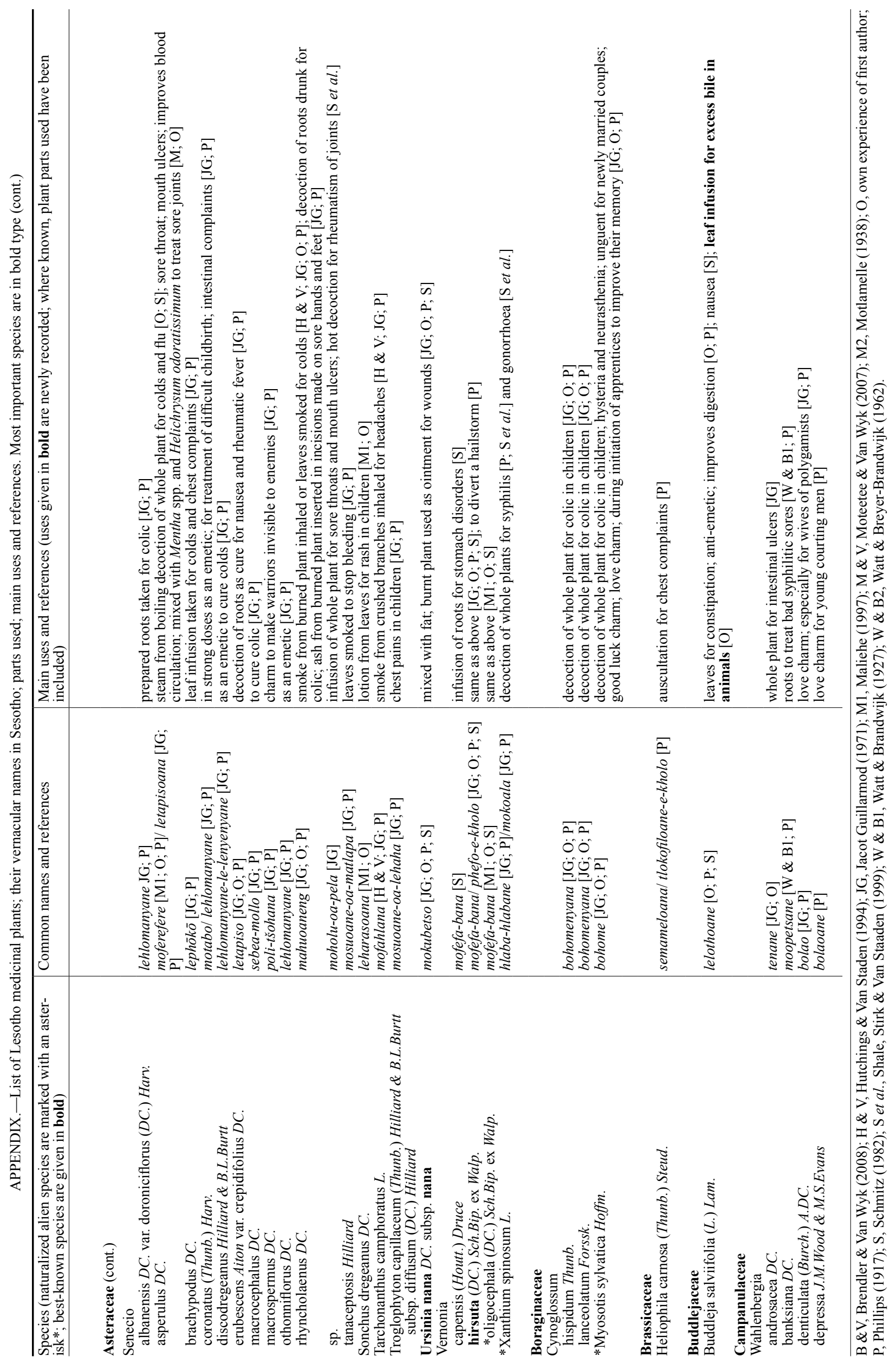




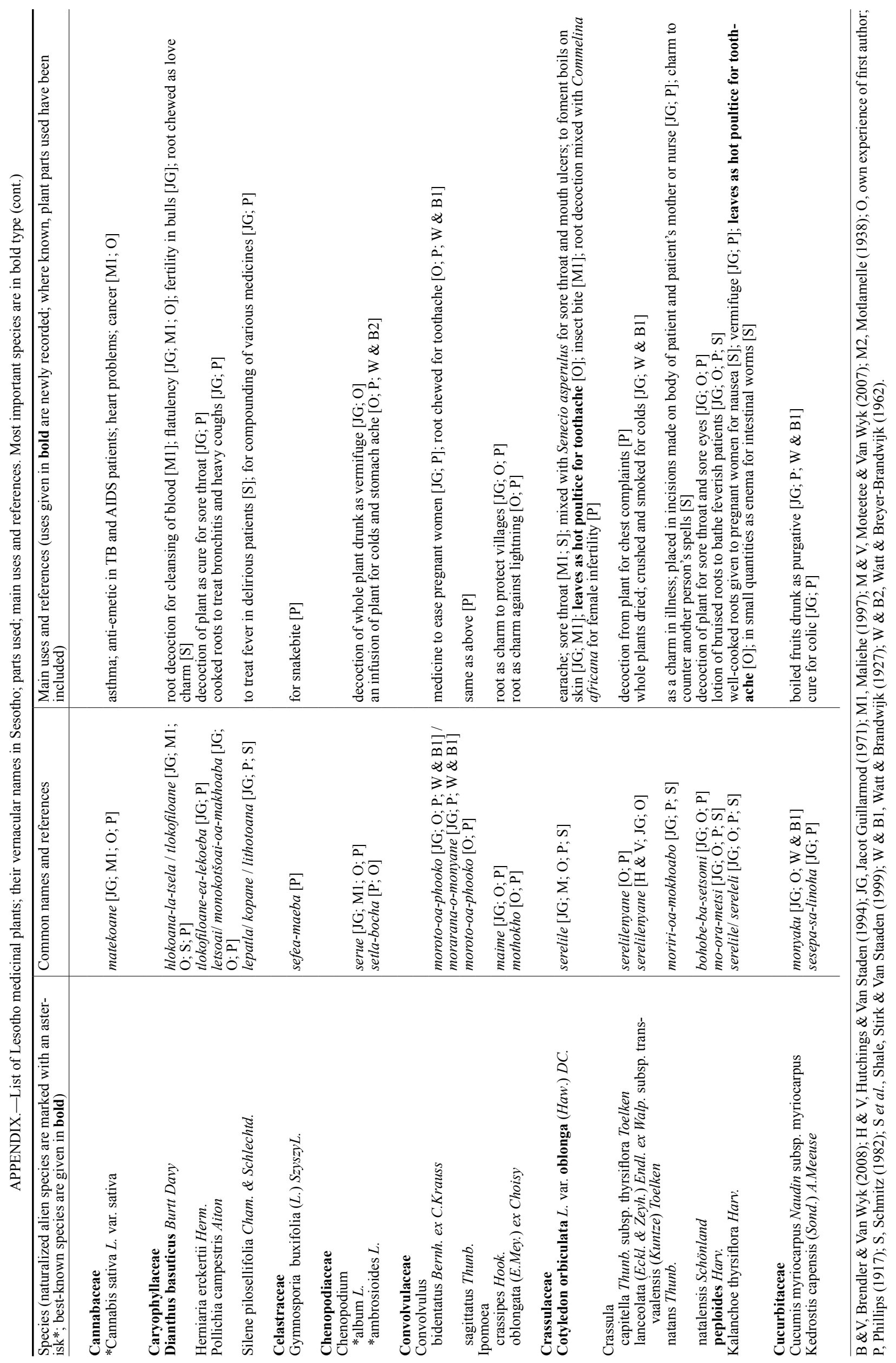




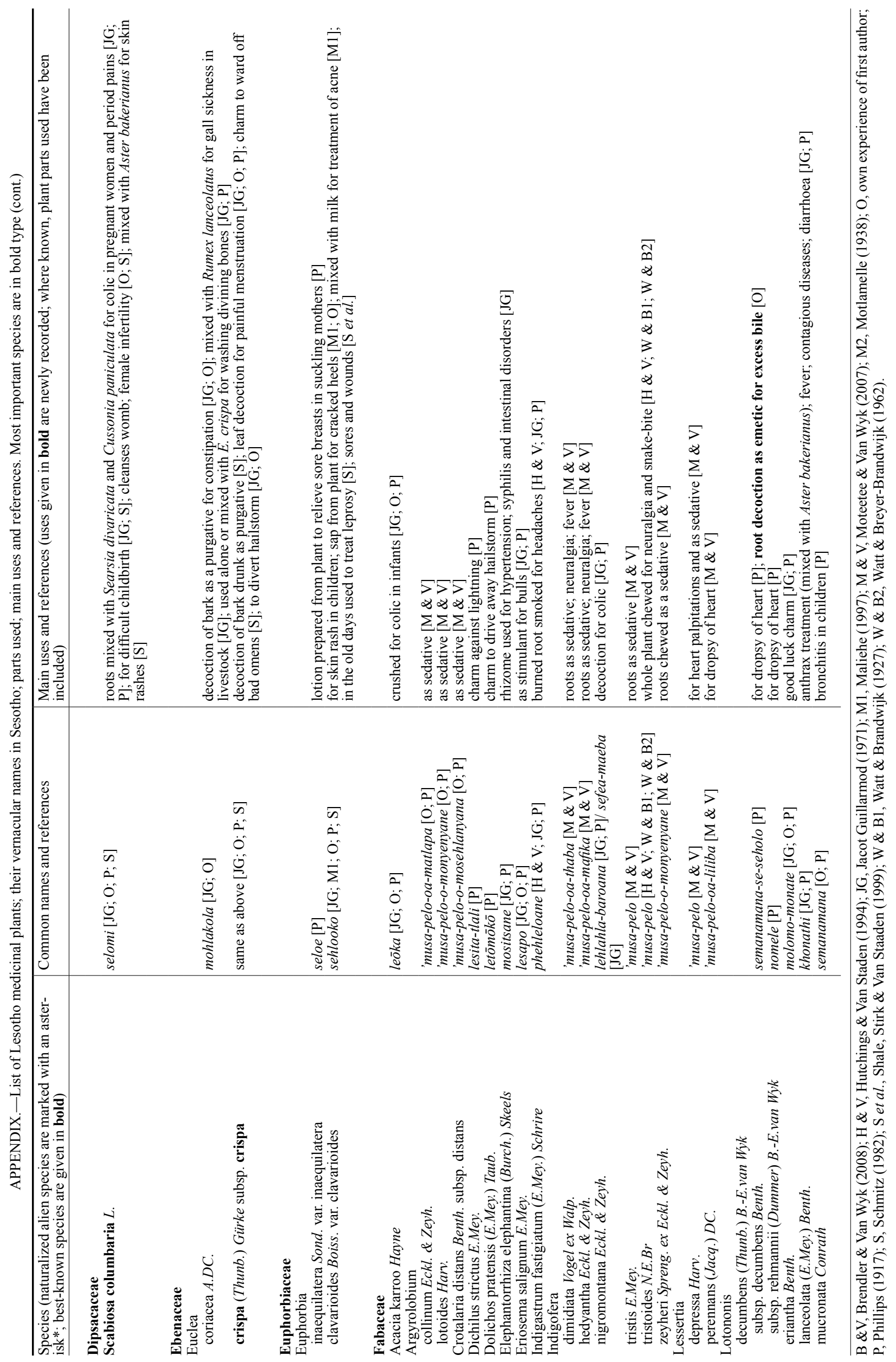




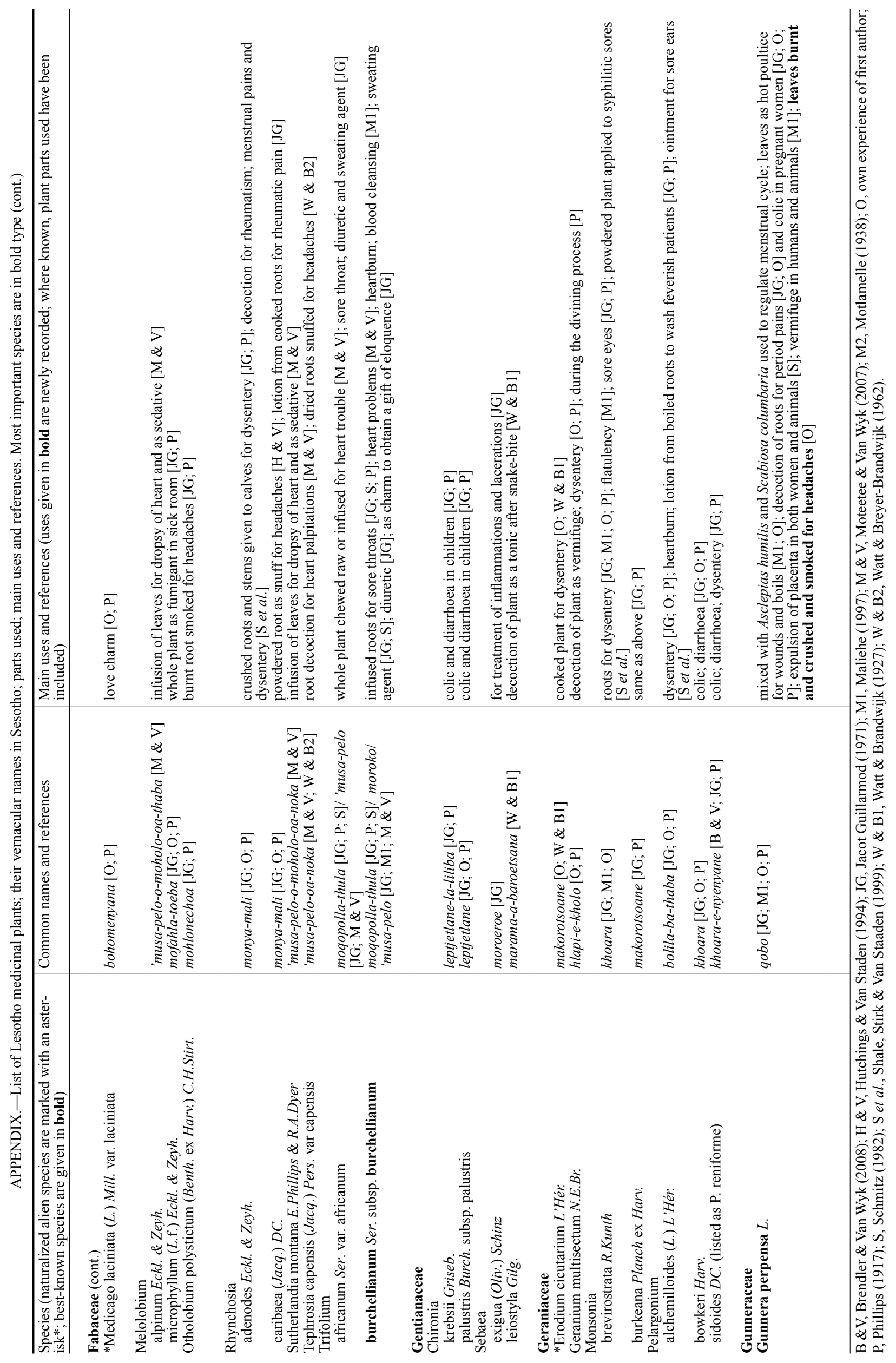




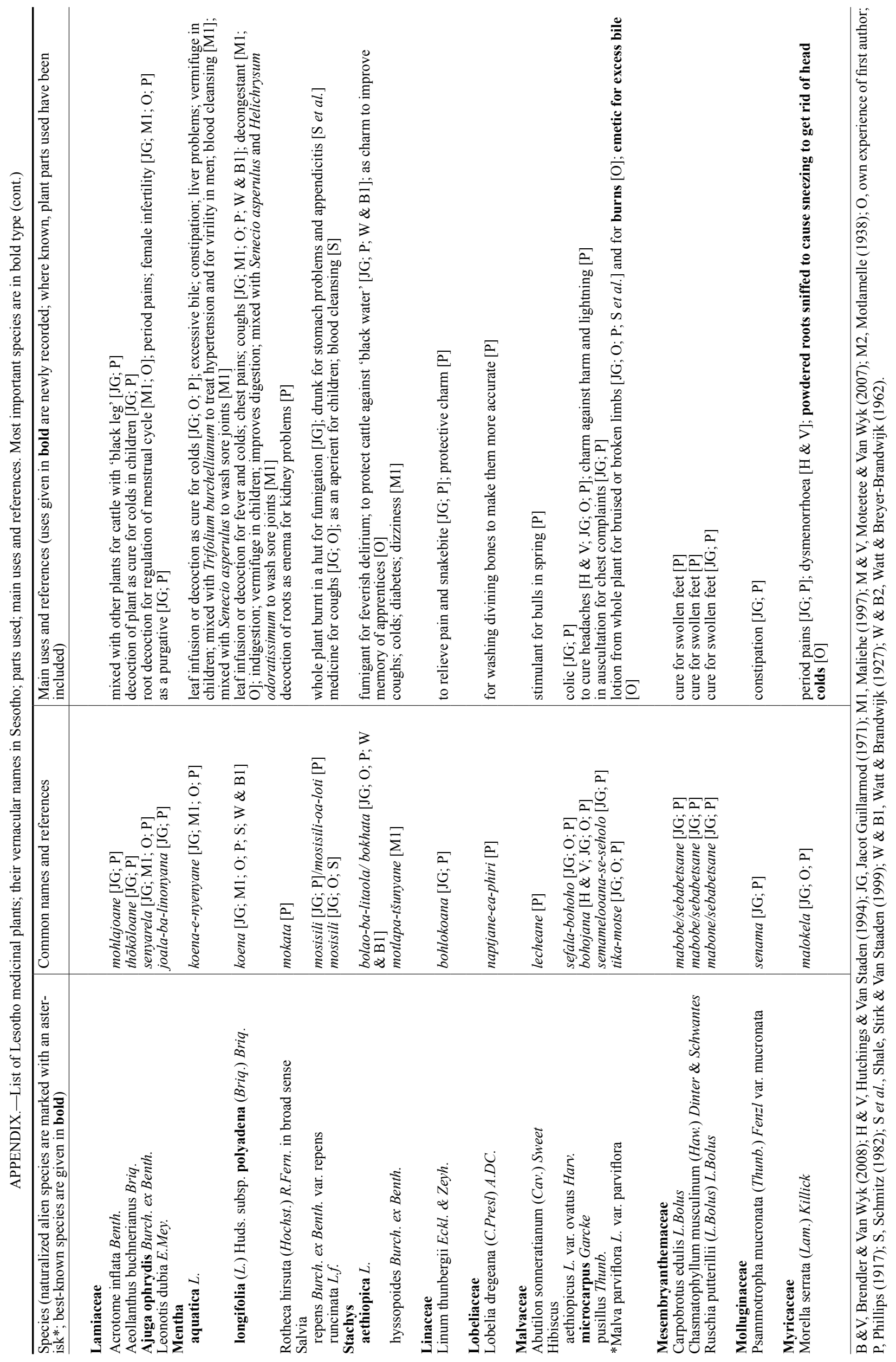




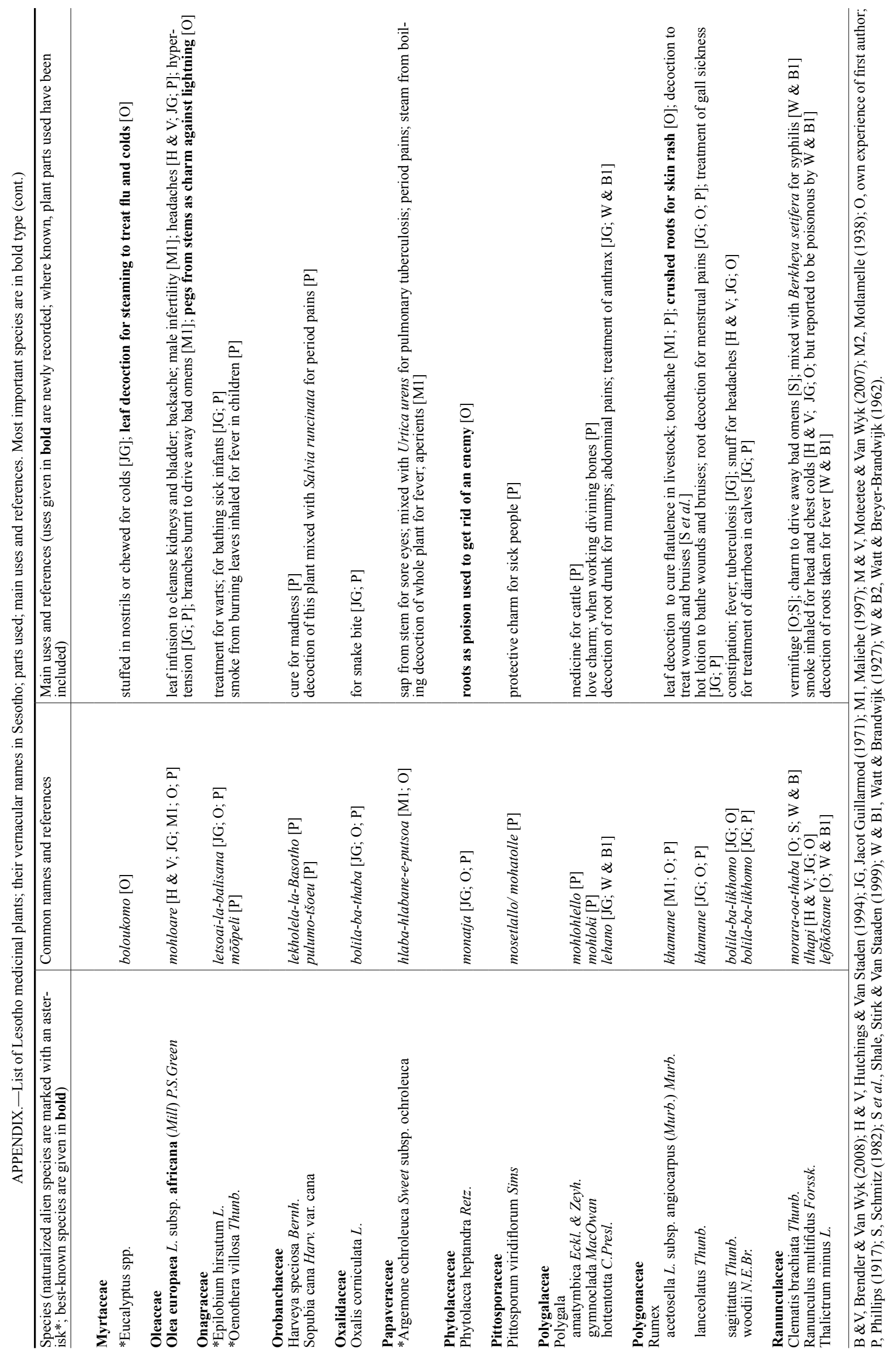




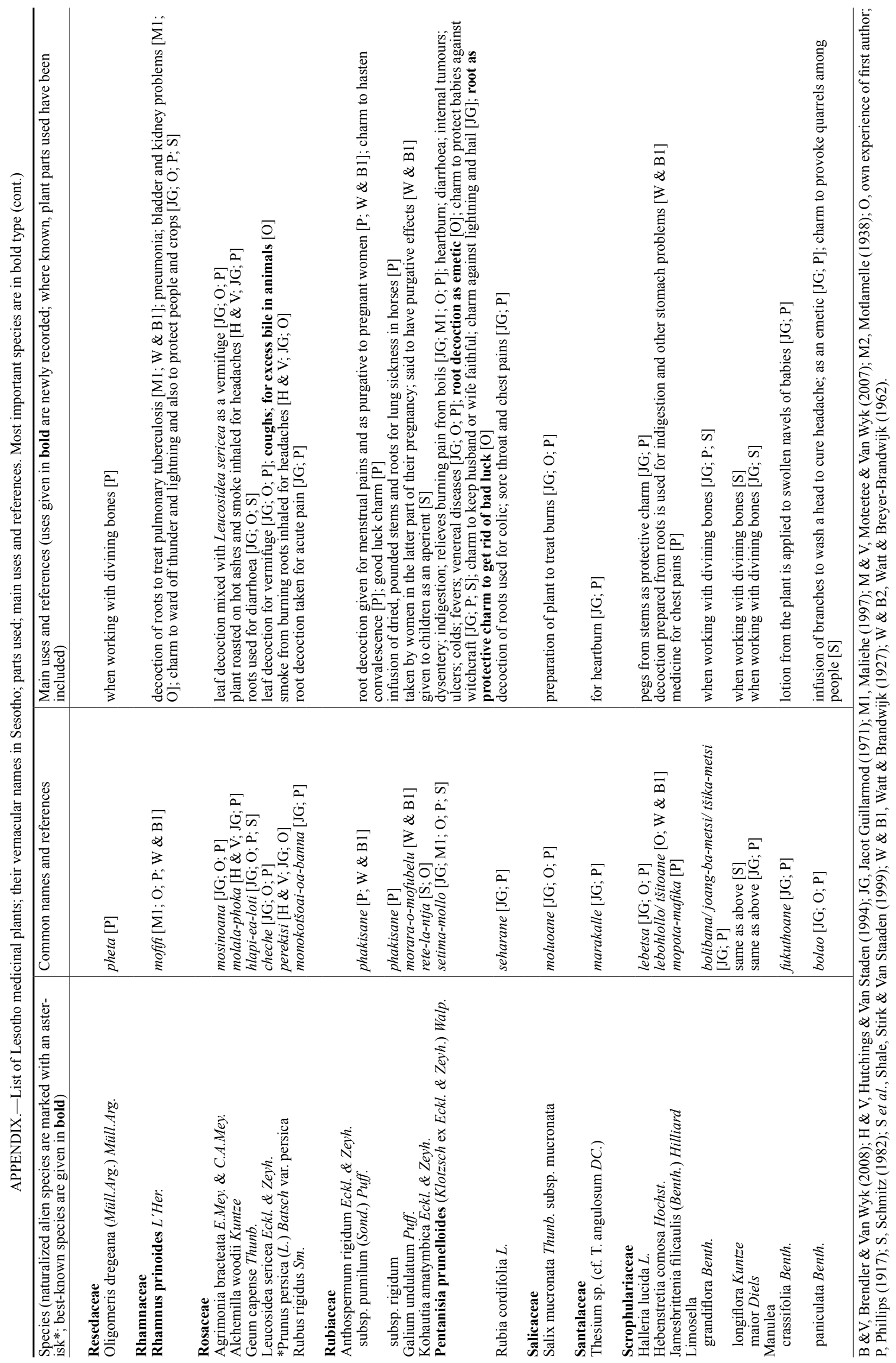




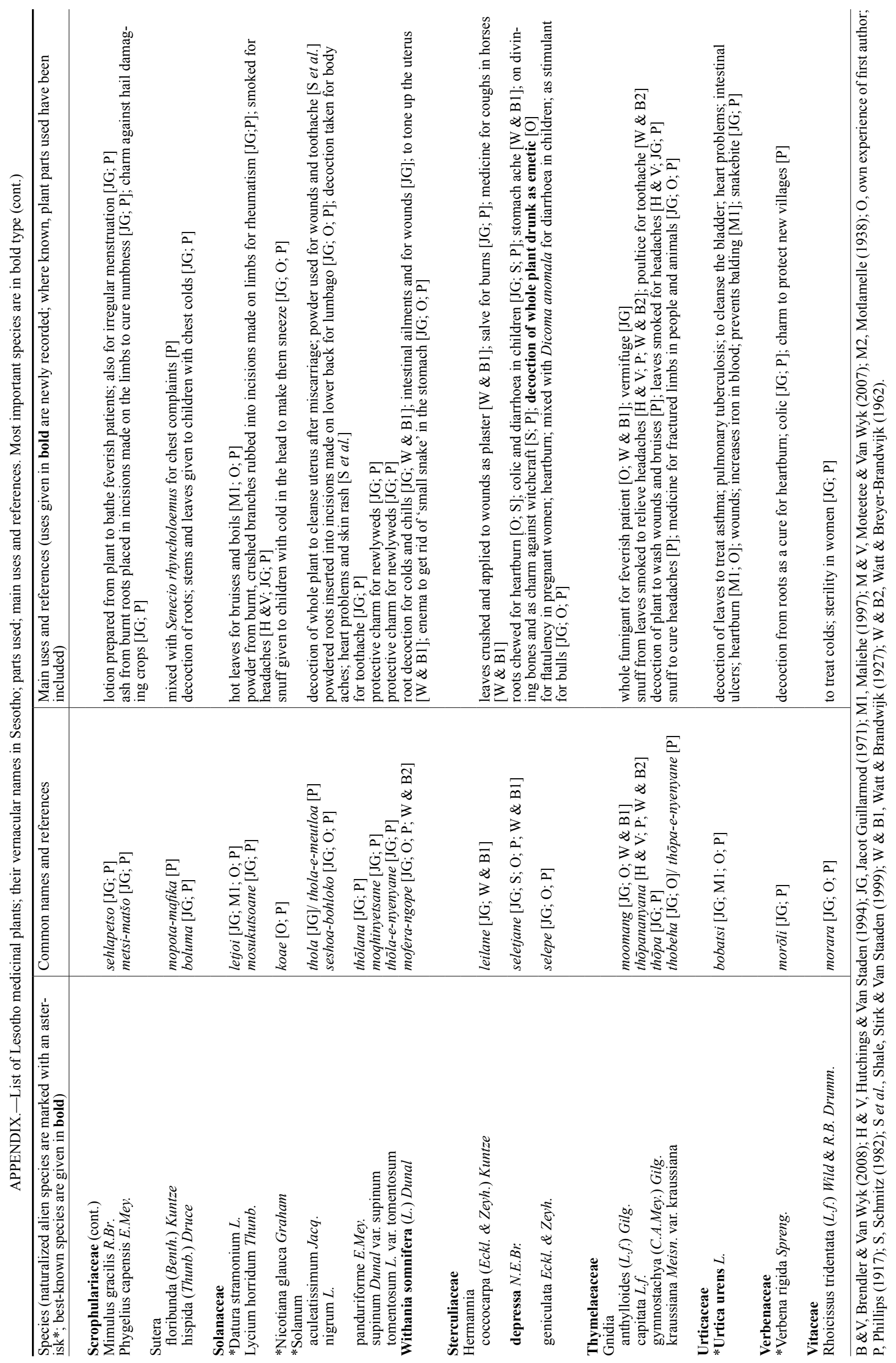




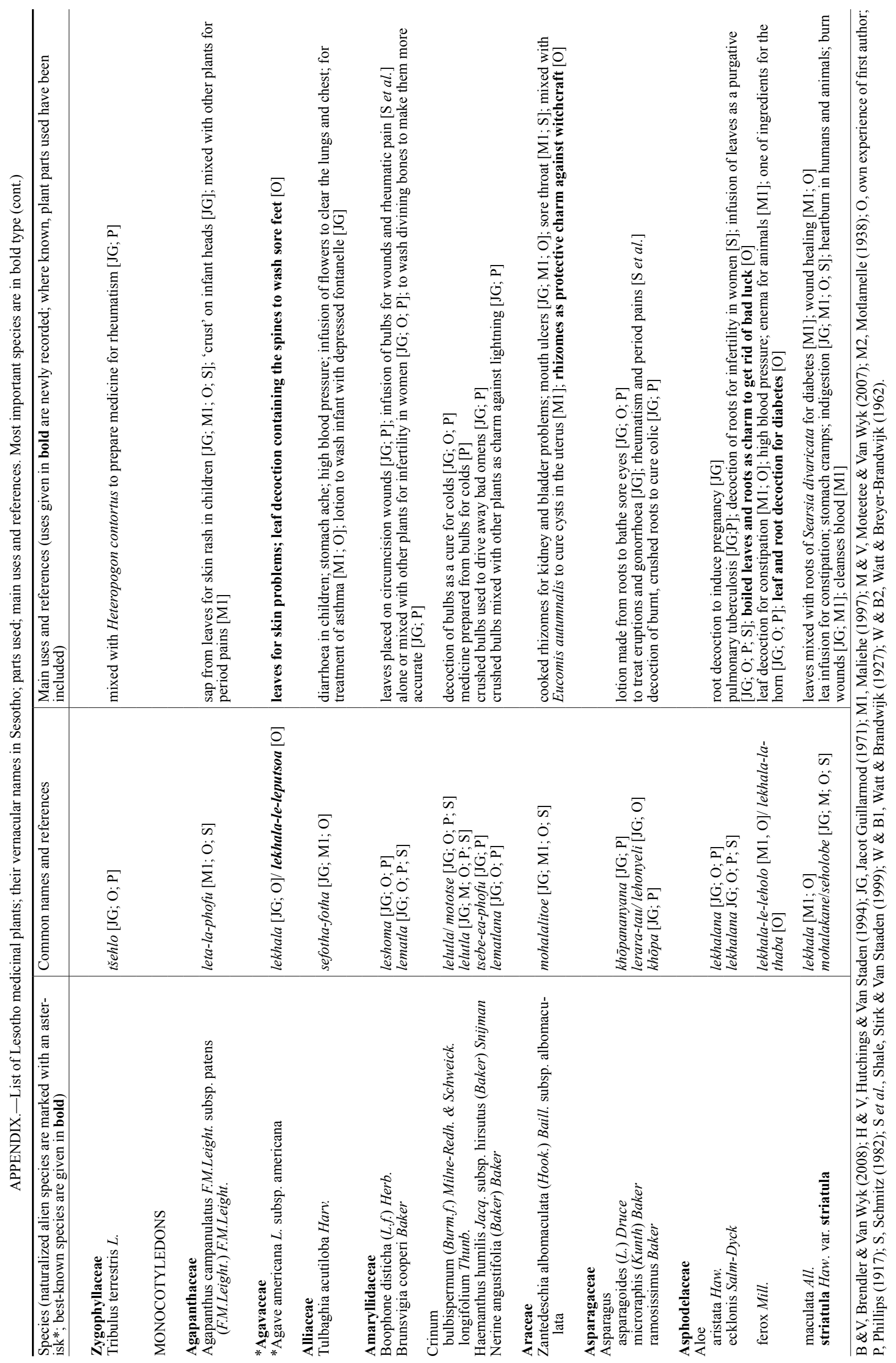




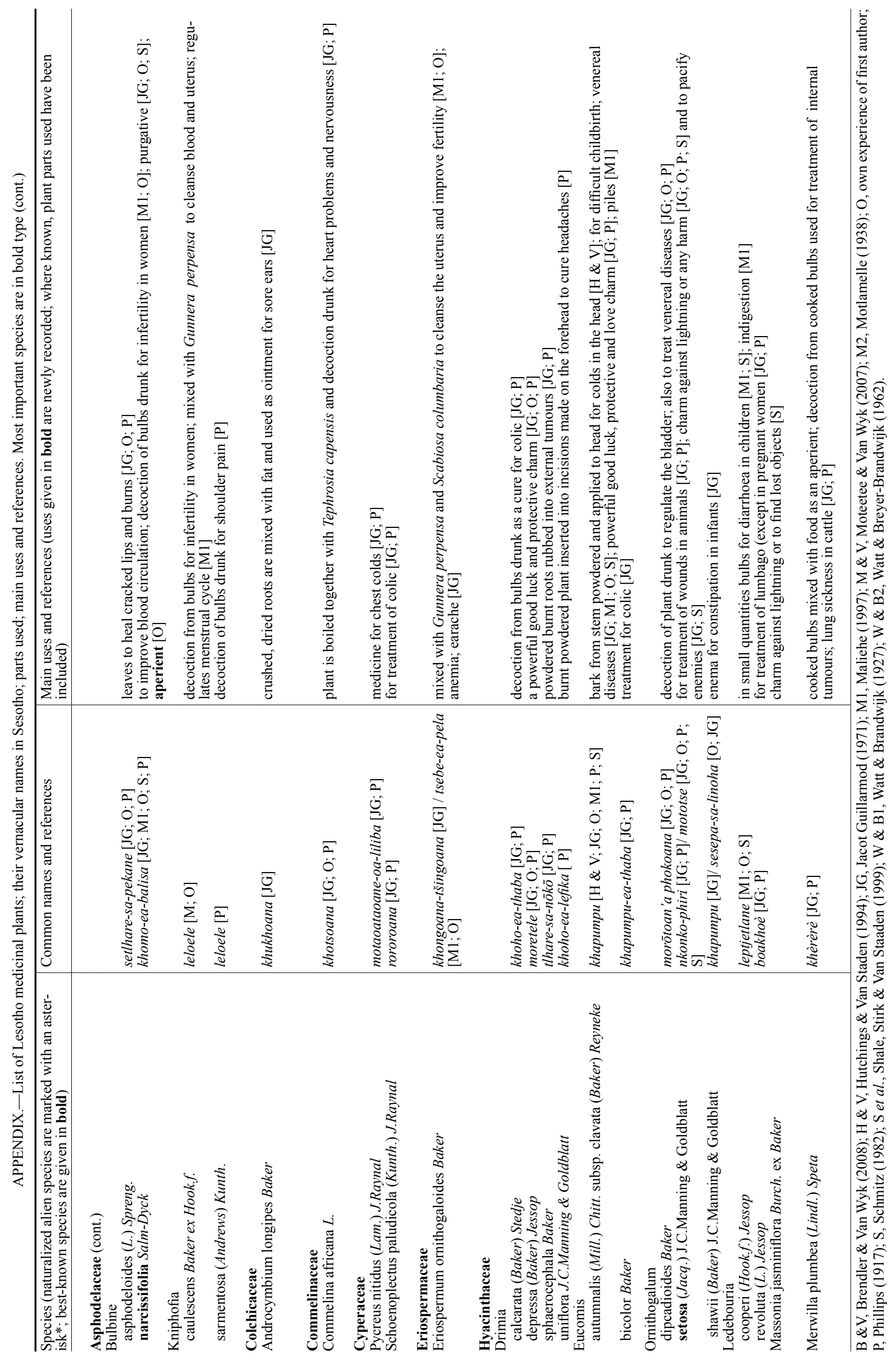




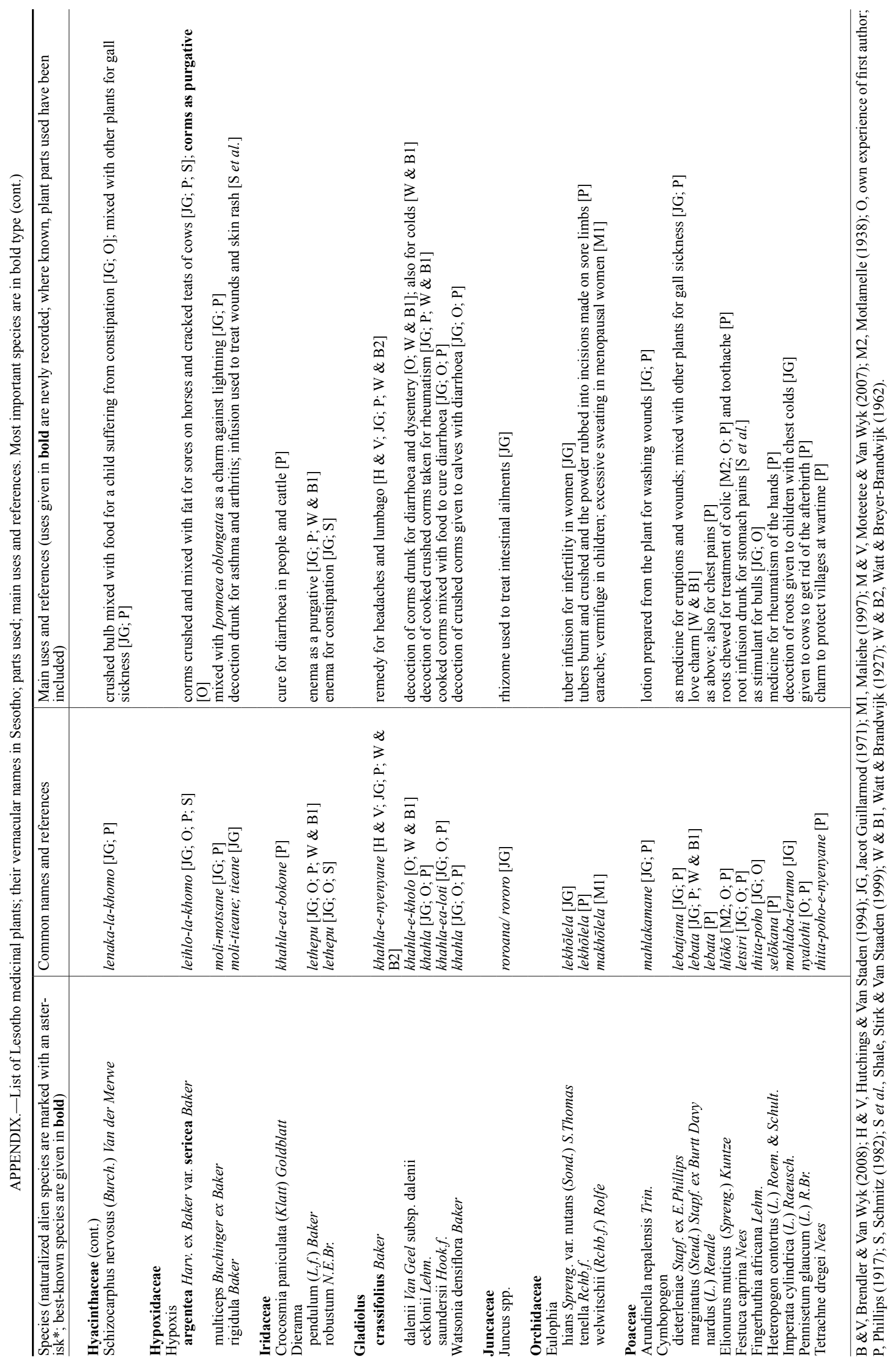

